\title{
TU/e EmonONEN

\section{Revealing an intermediate region between the collisional radiofrequency plasma bulk and its sheath}

\section{Citation for published version (APA):}

Beckers, J., Trienekens, D. J. M., \& Kroesen, G. M. W. (2015). Revealing an intermediate region between the collisional radiofrequency plasma bulk and its sheath. Physical Review E - Statistical, Nonlinear, and Soft Matter Physics, 91(3), 1-5. [033109]. https://doi.org/10.1103/PhysRevE.91.033109

DOI:

10.1103/PhysRevE.91.033109

Document status and date:

Published: 18/03/2015

\section{Document Version:}

Publisher's PDF, also known as Version of Record (includes final page, issue and volume numbers)

\section{Please check the document version of this publication:}

- A submitted manuscript is the version of the article upon submission and before peer-review. There can be important differences between the submitted version and the official published version of record. People interested in the research are advised to contact the author for the final version of the publication, or visit the $\mathrm{DOI}$ to the publisher's website.

- The final author version and the galley proof are versions of the publication after peer review.

- The final published version features the final layout of the paper including the volume, issue and page numbers.

Link to publication

\section{General rights}

Copyright and moral rights for the publications made accessible in the public portal are retained by the authors and/or other copyright owners and it is a condition of accessing publications that users recognise and abide by the legal requirements associated with these rights.

- Users may download and print one copy of any publication from the public portal for the purpose of private study or research.

- You may not further distribute the material or use it for any profit-making activity or commercial gain

- You may freely distribute the URL identifying the publication in the public portal.

If the publication is distributed under the terms of Article 25fa of the Dutch Copyright Act, indicated by the "Taverne" license above, please follow below link for the End User Agreement:

www.tue.nl/taverne

Take down policy

If you believe that this document breaches copyright please contact us at:

openaccess@tue.nl

providing details and we will investigate your claim. 


\title{
Revealing an intermediate region between the collisional radiofrequency plasma bulk and its sheath
}

\author{
J. Beckers, D. J. M. Trienekens, and G. M. W. Kroesen \\ Department of Applied Physics, Eindhoven University of Technology, P.O. box 513, 5600 MB, Eindhoven, the Netherlands
}

(Received 25 June 2014; revised manuscript received 13 October 2014; published 18 March 2015)

\begin{abstract}
Experimental evidence of the existence of an intermediate region between a capacitively coupled plasma and the collisional space-charge region at its borders is presented. This proof is generated by monitoring-in an airplane carrying out parabolic flights - the trajectory of plasma-confined microparticles. Based on only primary data and without the need for a sophisticated model, our analysis concludes a sharply marked transition from the sheath region into another region with a significantly lower-yet nonzero-space-charge density, i.e., a region which is often called the presheath.
\end{abstract}

DOI: 10.1103/PhysRevE.91.033109

PACS number(s): $52.40 . \mathrm{Kh}, 52.70 . \mathrm{Nc}$

\section{INTRODUCTION}

It was not until 1923 that Irving Langmuir described for the first time the plasma sheath, which is a region-self-induced by the plasma-in the vicinity of a surface when the plasma is in contact with that surface [1]. In the sheath region, massive electric fields are created since free electrons close to the surface are depleted, leaving the positive ions and hence a significant space charge. Being widely utilized in almost every plasma application because of its ability to accelerate positive ions towards surfaces, the concept of the plasma sheath is of major importance. However, today the transition between the quasineutral plasma bulk and the plasma sheath is still far from understood.

The plasma to sheath problem has been modeled extensively over the past 85 years using several approaches [2-5]. The major problem was to mathematically match the potentials at the border between the bulk plasma (no electric fields since electron and ion densities are equal) and the sheath (large electric fields due to depletion of electrons).

In 1949 Bohm [6] proposed for collisionless and weakly collisional plasmas the introduction of an intermediate layerthe presheath. In this layer, ions from the plasma bulk are expected to be accelerated up to a certain finite velocitythe Bohm velocity-before entering the sheath. For weakly collisional plasmas, the typical length of this region is close to the ion-neutral mean free path length [7]. The impact of better understanding the presheath structure not only limits to the wide range of applications mentioned above, but will be significant from a fundamental point of view to the full field of plasma physics. This because ions from the full plasma volume are-besides bulk recombination which is very limited at low pressures-lost via the sheath and plasma-surface chemistry occurs per definition at the plasma boundaries only. Furthermore, knowledge about the presheath can be of major interest to interpret the ongoing complex plasma experiments in the International Space Station, enabling studying, for instance, physical phase transitions on a macroscopic scale $[8,9]$.

In the past, several groups have reported measurements of electric field profiles in the plasma sheath by means of Stark splitting [10] and Stark shift [11] and by means of Langmuir probe measurements [12]. However, spatially these measurements are limited to only those regions in which the electric field shows high values, i.e., close to the electrode. At positions closer to the quasineutral plasma bulk-where the electric fields are significantly lower and where the presheath is expected to exist - the above-mentioned methods appeared not suitable. Already for more than a decade, plasmaconfined microparticles have demonstrated their ability to act as electrostatic probes in plasmas under varying gravity conditions [13-17]. A major drawback of such a method is the fact that the particle levitation height differs with particle radius and therefore larger particles might be levitated at positions in the sheath significantly below the sheath edge [18]. Using dust particles as electrostatic probes requires either measurements with different particle radii or measurements where the levitation height is altered using external forces, such as the gravitational force $[19,20]$.

From the introduction of the presheath in 1949, it was not before 2002 that the first researchers claimed the experimental proof of its existence in the collisionless case [21]. In 2004, Takizawa et al. also explored this region by means of laser-induced fluorescence-dip spectroscopy [22]. Those experiments were conducted at very low gas pressures and hence very low collisionalities. At pressures as used in this study - 16-31 Pa (up to 500 times higher) - the sheath must be considered collisional and has a typical thickness of about $7 \mathrm{~mm}$ only [19]. It is because of this small length scale that under these conditions the existence of a possible intermediate layer between the sheath and the plasma bulk has never been explored experimentally. Therefore, there is a lot of discussion and uncertainty in literature regarding the possible existence, the shape, and the absolute values of the electric fields in the presheath and thus also regarding the validity of the idea that ions must be accelerated up to the Bohm velocity in the collisional case [13-25].

Here, we report experimental evidence of the existence of a sharply marked region between the quasineutral plasma bulk and the collisional space-charge region at its border, often named the presheath. This proof is generated by temporally monitoring the position of plasma-confined microparticles during a transition from hyper- to microgravity conditions during parabolic flights.

\section{EXPERIMENTAL CONFIGURATION}

The basis of the used experimental setup is identical to that used in Refs. $[19,20]$ and consists of a cubic $(20 \times 20 \times$ $20 \mathrm{~cm}^{3}$ ) vacuum chamber in which a low-pressure radiofrequency (rf) argon plasma is operated between two parallel and 
horizontally aligned squared $\left(7 \times 7 \mathrm{~cm}^{2}\right)$ electrodes separated $4 \mathrm{~cm}$. The applied rf frequency is $13.56 \mathrm{MHz}$ and the plasma power is $\sim 5 \mathrm{~W}$. Within the bulk of this plasma, the plasma density $\left[(7.0 \pm 1.4) \times 10^{14} \mathrm{~m}^{-3}\right]$ and electron temperature $(1.5 \pm 0.5 \mathrm{eV})$ were measured earlier with a Langmuir probe (Ref. [19]). From this, one can estimate an electron Debye length of approximately $0.34 \mathrm{~mm}$.

From the top, a dust injector provides the vacuum chamber with microparticles (Melamine-Formaldehyde particles with a radius of $4.9 \mu \mathrm{m}$ ). Once injected, the inserted microparticles fall through a hole in the upper-grounded-electrode after which they are charged negatively within the plasma and confined due to equilibrating forces above the bottom-rfpowered-electrode (see Fig. 1).

In this bottom electrode, a 1-mm-deep circular indent confines the microparticles horizontally. The size of this indent was chosen such that in the center, and a few millimeters around, the equipotential surface was horizontally flat [19]. The confined microparticles are illuminated by an expanded $532 \mathrm{~nm}, 300 \mathrm{~mW}$ laser beam, while its position is recorded at 50 frames per second by a modified CCD camera placed behind a $532 \mathrm{~nm}$ interference filter. The vacuum system, power supplies, optics, pumping unit, and gas supplies (argon) are mounted in a frame in the Novespace Airbus A300 airplane carrying out parabolic flights. In such parabolic flights the airplane (1) flies steadily at fixed height, (2) pulls up for about $20 \mathrm{~s}$ during which the apparent gravitational level is approximately $1.8 \mathrm{~g}_{0}$ (here $\mathrm{g}_{0}$ is the normal gravitational acceleration on earth $\left.\left[9.81 \mathrm{~m} / \mathrm{s}^{2}\right]\right),(3)$ lowers its engine power such that it just overcomes its air friction (microgravity period for about $25 \mathrm{~s}$ ), and, finally, (4) pulls up (again hypergravity conditions of roughly $1.8 \mathrm{~g}_{0}$ for about $20 \mathrm{~s}$ ). In parallel with the recorded CCD images, the gravitational acceleration is measured by an accelerometer at $50 \mathrm{~Hz}$. An electronic system synchronizes the recorded movies with the data of the gravitational acceleration $g^{*}(t)$ in time $t$.

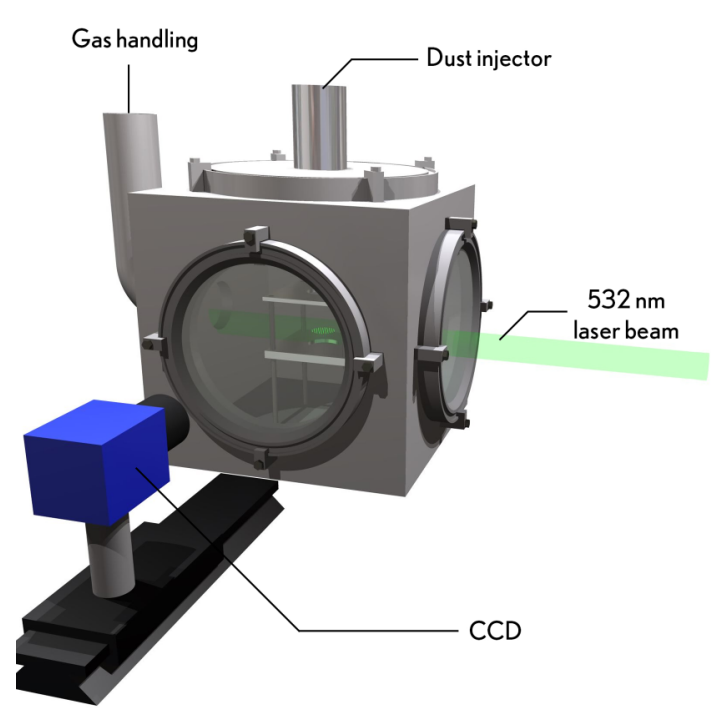

In these experiments-probing the upper regions of the plasma sheath and the transition into the plasma bulkthe hyper-to-microgravity transition is of special interest. Therefore, in this manuscript the focus is on this phase only.

During the parabolic flights, the followed procedure was as follows. Just before one parabola the vacuum vessel was pumped down and filled up to the desired pressure with pure argon gas. Then, a few microparticles were injected and confined in the plasma after which the vessel was sealed (no gas flows). At one time, only a few (between one and twenty) microparticles were levitated, all within one layer in the horizontal plane. By carefully observing the situation of one single particle and comparing this to the situation with several microparticles within one layer, it was earlier shown that using a few particles does not impact the sheath nor the particle equilibrium position [19]. Just before and through all phases of the parabola data are taken from the CCD camera and the accelerometer.

\section{RESULTS AND INTERPRETATION}

Figure 2 plots for three pressures both the apparent gravitational acceleration $g^{*}$ and the particle height $z$ as a function of time till just after the hyper-to-microgravity transition. Behavior as expected can be observed from this figure, i.e., at higher values of $g^{*}$ the particle is pushed closer towards the bottom electrode and vice versa. The reason that the particle can be confined is the fact that the forces working on it are in equilibrium. Since gas flows are absent and the used laser power per surface area is relatively low we can safely neglect neutral drag and irradiation forces on the particle [19]. Forces that do work on the particle are (1) the time-averaged electrostatic force $\left\langle F_{E}\right\rangle_{t}$ due to the time-averaged local electric field $\langle E\rangle_{t}$ in the sheath working on

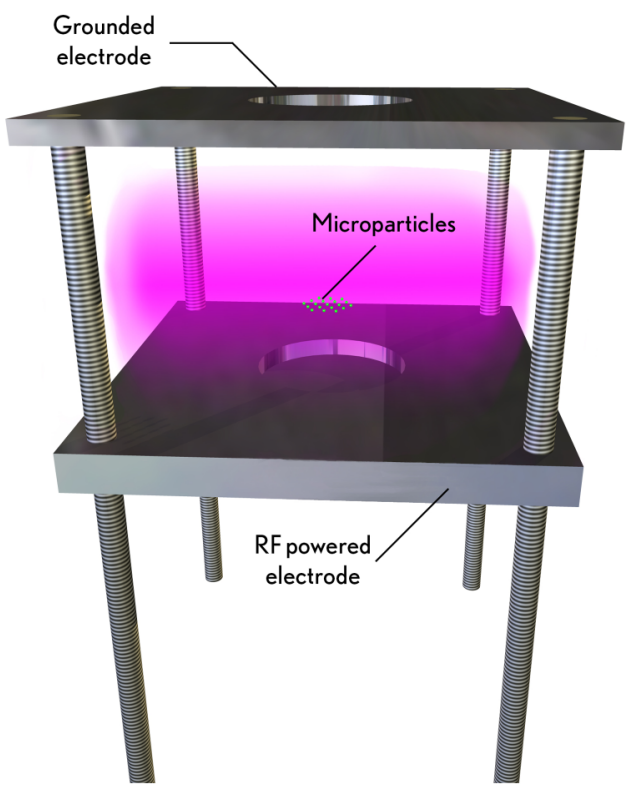

FIG. 1. (Color online) Representation of the experimental configuration as mounted inside the Airbus A300 zero-g airplane. 


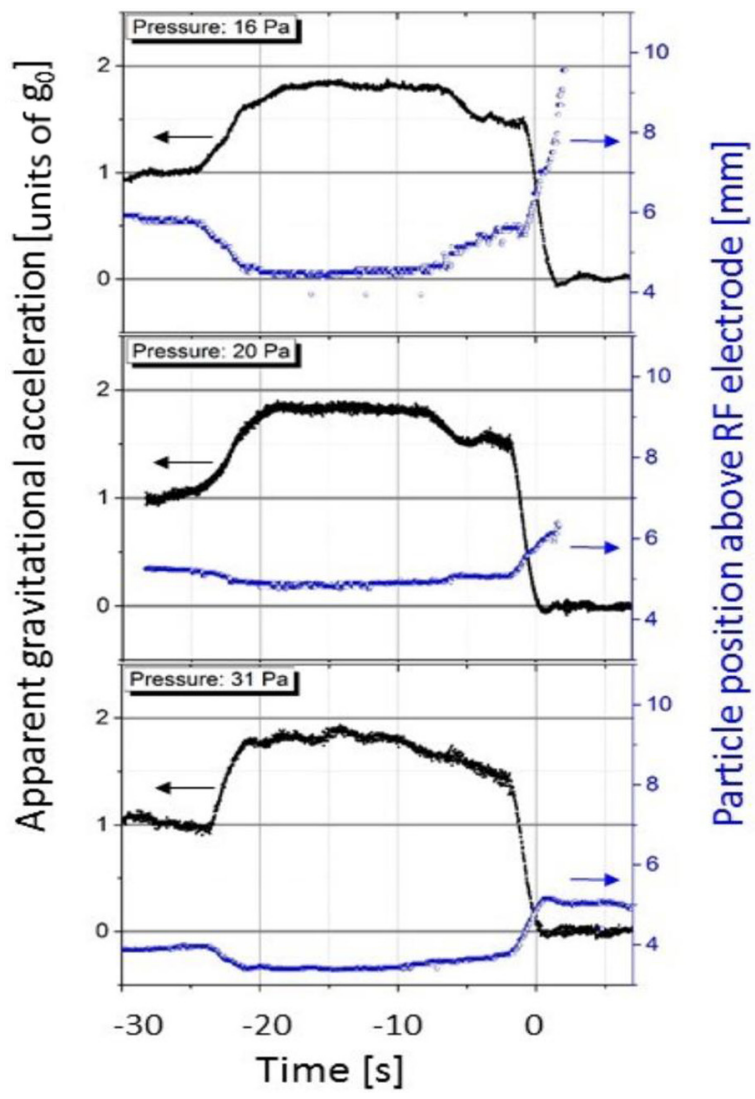

FIG. 2. (Color online) Apparent gravitational acceleration together with the (vertical) particle position above the rf electrode during the first hypergravity period and the beginning of the microgravity period.

the time-averaged negative particle charge $\langle Q\rangle_{t}$ (directed away from the bottom electrode), (2) the total time-averaged ion drag force $\left\langle F_{i}\right\rangle_{t}$ (both orbital ion drag force and collection ion drag force contributions included) due to positive ions-accelerated in the sheath electric field-transferring their momentum to the particle (directed towards the bottom electrode), and, of course, (3) the apparent gravitational force (directed towards the bottom electrode). Note that-although particle charge and local electric fields vary during the course of a single rf cycle - the inertia of the particle is sufficiently high to only take into account time-averaged values (denoted with \langle\rangle$_{t}$ ) of the several parameters and forces. The same accounts for local values of the electron density $\left\langle n_{e}\right\rangle_{t}$, the ion density $\left\langle n_{i}\right\rangle_{t}$, and the space-charge density $\langle\rho\rangle_{t}$, where only time-averaged values are taken into account when discussing particle charging mechanisms and the creation of local electric fields. Changes of the time-averaged forces working on the particle are slow enough to neglect particle inertia and, hence, force equilibrium at all particle positions can be safely assumed. Also, the velocity of the particle with respect to the plasma is low enough $(2 \mathrm{~mm} / \mathrm{s})$ to safely neglect significant influences of friction forces. Further we point to the fact that all forces working on the particle are parallel, i.e., perpendicular to the electrode. Although the circular indent in the bottom electrode prevents particles from being lost in the horizontal direction, it is verified that the equipotential surface is horizontal above the indent's center and a few millimeters around [19].

As can be observed from the plots in Fig. 2, at high pressure $(31 \mathrm{~Pa})$ the particles remain confined during the microgravity phase while at the two other pressures $(16 \mathrm{~Pa}$ and $20 \mathrm{~Pa}$ ) the particles are lost from the discharge within or after the transition from hyper- to microgravity conditions. In the framework of the current paper, it is especially this transition we are interested in. For interpretation of the primary data presented in Fig. 2 we plot-for the pressures at which the particle is lost from the discharge-the particle height $z$ above the electrode as a function of apparent gravitational acceleration $g^{*}$ in Fig. 3 and focus only on the hyper- to microgravity transition. In both plots in Fig. 3, three regions can be distinguished, denoted as region I, region II, and region III.

Already from these sets of primary data alone, the existence of an intermediate region can be concluded. In region I and region II one can observe a monotonic increasing particle height at decreasing gravitational levels.

In these regions, i.e., close to surfaces, walls, and electrodes, it must be noted that the electric field is a function of distance to the surface due to depletion of free electrons. This depletion at the same time alters the charge the particle will acquire, making the time-averaged charge position dependent in these regions.

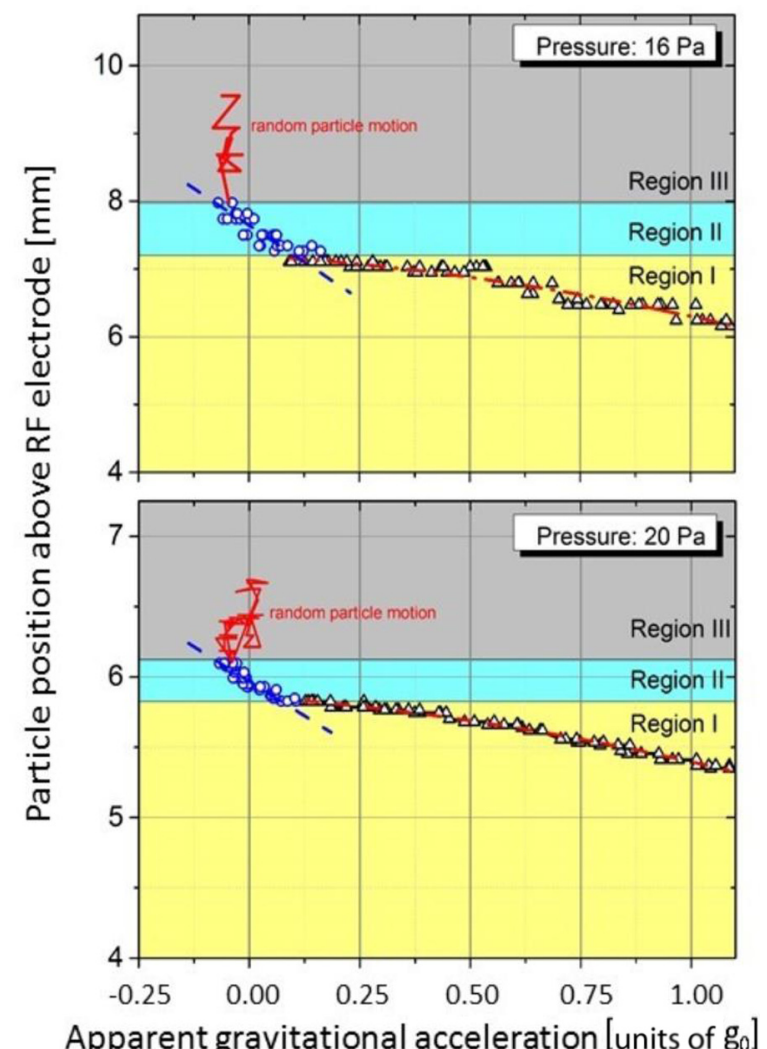

FIG. 3. (Color online) (Vertical) particle position above the $\mathrm{rf}$ electrode as a function of apparent gravitational acceleration at gas pressures of $16 \mathrm{~Pa}$ (top figure) and $20 \mathrm{~Pa}$ (bottom figure). To help the reader's eye, smooth lines have been drawn through the data points in the regions I and II. 
Since the ion drag force depends on both the local electric field (via the directed ion velocity) and the particle charge, the ion drag force depends on position in the sheath as well. Stable particle confinement in regions I and II means that at all these particle positions the net result of all forces working on the particle is zero. Although from these data sets it is not possible to obtain information about absolute values of $\left\langle F_{E}\right\rangle_{t}$ and $\left\langle F_{i}\right\rangle_{t}$, the monotonic behavior of lower particle equilibrium positions at higher values of $g^{*}\left(\propto F_{g}\right)$ indicates the presence of force gradients. This means that an electric field $E$ must be present and significant in both regions. The situation in region III, however, is different. In this region, very small vibrations in the apparent gravitational level lead to randomized motion of the particle in the $z$ direction (see Fig. 3). This indicates that in this region small variations in $g^{*}$ (and thus small variations in the apparent gravitational acceleration) fully dominate all other (ion drag and electrostatic) forces mentioned earlier and that it can be concluded that the local electric field has a very low value, i.e., this region represents the quasineutral plasma bulk. The fact that-despite of its randomized motion-the particle remains in the vicinity of the region II-III transition for a while indicates that, although not dominant, even within the quasineutral plasma bulk the electric field is nonzero.

The conclusion that-next to the quasineutral plasma bulk (region III, with $E$ close to zero) and the plasma sheath (region I, with $E \gg 0$ ) above the rf electrode-a third region (region II) with $E>0$ separating them must exist is clearly demonstrated by the kink in the $g^{*}-z$ profiles at the transitions from region I to region II.

A possible explanation for the sudden increase in slope $\left|d z / d g^{*}\right|_{\text {region_II }}>\left|d z / d g^{*}\right|_{\text {region_I }}$ can be found by reviewing a basic sheath model and the general orbital motion limited (OML) theory [26]. In region III the space-charge density is close to zero since on average $\left\langle n_{e}(z)\right\rangle_{t} \approx\left\langle n_{i}(z)\right\rangle_{t}$. In region I, electrons are depleted, $\left\langle n_{e}(z)\right\rangle_{t} \ll\left\langle n_{i}(z)\right\rangle_{t}$, and hence the space charge induces according to Poisson's equation,

$$
\frac{d\langle E\rangle_{t}}{d z}=\frac{e}{\varepsilon_{0}}\langle\rho(z)\rangle_{t}=\frac{e}{\varepsilon_{0}}\left[\left\langle n_{i}(z)\right\rangle_{t}-\left\langle n_{e}(z)\right\rangle_{t}\right],
$$

a significant electric field gradient. Region II, however, can be seen as the transition region where $\left\langle n_{e}(z)\right\rangle_{t}$ is indeed smaller than $\left\langle n_{i}(z)\right\rangle_{t}$ but where the electrons are not as significantly depleted as is the case in region I. With increasing height above the electrode, this initiates two effects when region II is compared to region I. (1) The space charge becomes significantly smaller, meaning a smaller electric-field gradient. (2) OML theory would predict the time-averaged particle charge-being determined by balancing electron and ion currents towards the particle's surface - to increase significantly due to enhanced electron density in region II. Earlier measurements in similar plasma configuration have shown particle charges of $8 \times 10^{3} e^{-}$in the sheath (region I) [19], while estimates with OML theory predict values of about $2 \times 10^{4} e^{-}$in the bulk (region III).

To summarize, in both region I and region II the present time-averaged electric field is larger than zero, while a clear kink in the $g^{*}-z$ profile sharply marks the transition between both regions. This clearly indicates the entrance from the sheath region into a region with nonzero electric fields, i.e., a region often called the presheath.

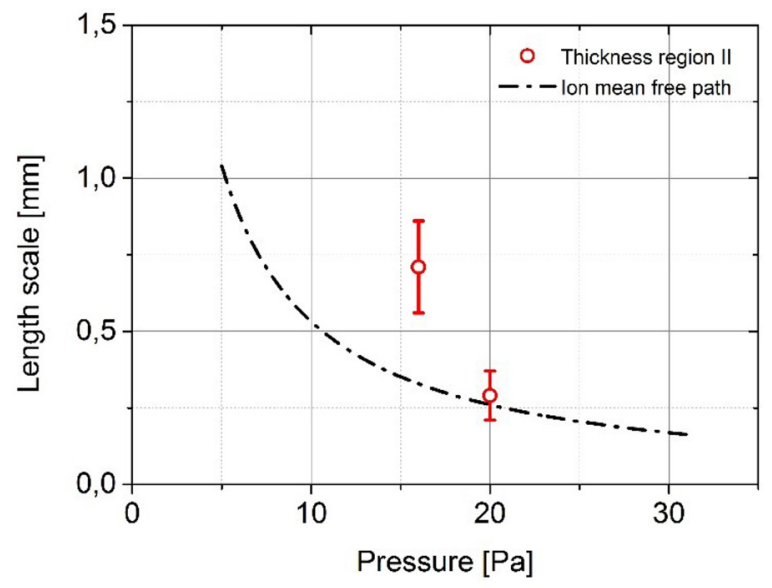

FIG. 4. (Color online) Theoretical value of the ion mean free path as a function of gas pressure together with experimentally determined values of the thickness of region II for $16 \mathrm{~Pa}$ and $20 \mathrm{~Pa}$.

Also, the thickness of region II-plotted for both pressures in Fig. 4-appears to be in the order of the ion mean-free path $\lambda_{\text {ion }}=\left(n_{n} \sigma_{i-n}\right)^{-1}$ through the background gas (plotted as a function of pressure in Fig. 4 as well). Estimating $\lambda_{\text {ion }}$ at for instance $16 \mathrm{~Pa}$ and $20 \mathrm{~Pa}$ with a gas density of $n_{n}=3.8 \times$ $10^{21} \mathrm{~m}^{-3}$ and $n_{n}=4.8 \times 10^{21} \mathrm{~m}^{-3}$, respectively, and with an ion-neutral collision cross section $\sigma_{i-n}=8 \times 10^{-19} \mathrm{~m}^{2}$ [27], we find $\lambda_{\text {ion }}=0.33 \mathrm{~mm}$ and $\lambda_{\text {ion }}=0.26 \mathrm{~mm}$, respectively. Although not exactly the same, these length scales are at least in the same order as the thicknesses of region II as determined from our experiments $(0.7 \pm 0.2 \mathrm{~mm}$ and $0.29 \pm 0.08 \mathrm{~mm}$ at $16 \mathrm{~Pa}$ and $20 \mathrm{~Pa}$, respectively) and have the trend as a function of pressures as one should expect (see Fig. 4). The suggestion that the thickness of the presheath in the collisional case would be in the order of the ion mean-free path has been theoretically predicted in literature before [7]. Although more data points would have been very welcome to deepen out the phenomena's dependence on pressure, we must point to the experimental difficulties in obtaining more data points. At higher pressures, the particle remains confined during microgravity conditions which gives-for not too high pressures-possibilities to detect the beginning of region II only. The transition into the plasma bulk cannot be detected and hence the thickness of region II cannot be determined. For pressures lower than 16 $\mathrm{Pa}$, the particles are lost from the discharge at velocities which are too high to perform measurements accurately with the current experimental configuration.

\section{CONCLUSIONS}

In conclusion, we present experimental evidence of the existence of a sharply marked region between the bulk of a collisional radiofrequency driven plasma and the collisional sheath at its border. This conclusion is based on interpreting only primary data of the particle confinement position under varying apparent gravitational levels. Without the need of a sophisticated model, our analysis concludes a sharply marked transition region from the sheath region into another region with a significantly lower-yet nonzero-space-charge density, i.e., a region which is often called the presheath. 


\section{ACKNOWLEDGMENTS}

This research was financially supported by ESA Grant No. 21045/07/NL/VJ, and by the Netherlands Space Office, SRON. The authors are grateful to ESA and Novespace for having this project participating in their 54th parabolic flight campaign. Finally, Ab Schrader is especially acknowledged for his skilled support upfront and during the measurement campaign.
[1] I. Langmuir, Science 58, 290 (1923).

[2] L. Tonks and I. Langmuir, Phys. Rev. 34, 876 (1929).

[3] S. A. Self and H. N. Ewald, Phys. Fluids 9, 2486 (1970).

[4] G. A. Emmert, R. M. Wieland, A. T. Mense, and J. N. Davidson, Phys. Fluids 23, 803 (1980).

[5] K.-U. Riemann, Phys. Plasmas 4, 4158 (1997).

[6] D. Bohm, The Characteristics of Electrical Discharges in Magnetic Fields, edited byA. Guthrie and R. Wakerling (McGrawHill, New York, 1949).

[7] J. A. Meyer, G. H. Kim, M. J. Goeckner, and N. Hershkowitz, Plasma Sources Sci. Technol. 1, 147 (1992).

[8] R. Seurig, G. Morfill, V. Fortov, and P. Hofmann, Acta Astronautica 61, 940 (2007).

[9] V. E. Fortov et al., Phys. Rep. 421, 1 (2005).

[10] U. Czarnetzki, D. Luggenholscher, and H. F. Dobele, Plasma Sources Sci. Technol. 8, 230 (1999).

[11] E. Wagenaars, M. D. Bowden, and G. M. W. Kroesen, Phys. Rev. Lett. 98, 075002 (2007).

[12] H. Yamada and D. L. Murphree, Phys. Fluids 14, 1120 (1971).

[13] B. M. Annaratone et al., New J. Phys. 5, 92 (2003).

[14] A. A. Samarian and B. W. James, Plasma Phys. Control. Fusion 47, B629 (2005).
[15] M. Kretschmer, S. A. Khrapak, S. K. Zhdanov, H. M. Thomas, G. E. Morfill, V. E. Fortov, A. M. Lipaev, V. I. Molotkov, A. I. Ivanov, and M. V. Turin, Phys. Rev. E 71, 056401 (2005).

[16] M. Rubin-Zuzic et al., New J. Phys. 9, 39 (2007).

[17] M. A. Fink et al., Phys. Rev. E 86, 065401(R) (2012).

[18] A. A. Samarian and B. W. Jamers, Phys. Lett. A 287, 125 (2001).

[19] J. Beckers, T. Ockenga, M. Wolter, W. W. Stoffels, J. van Dijk, H. Kersten, and G. M. W. Kroesen, Phys. Rev. Lett. 106, 115002 (2011).

[20] J. Beckers, D. J. M. Trienekens, and G. M. W. Kroesen, Phys Rev. E 88, 055101 (2013).

[21] L. Oksuz and N. Hershkowitz, Phys. Rev. Lett. 89, 145001 (2002)

[22] K. Takizawa, K. Sasaki, and A. Kono, Appl. Phys. Lett. 84, 185 (2004).

[23] H. B. Valentini, Phys. Plasmas 3, 1459 (1996).

[24] K. U. Riemann and P. Meyer, Phys. Plasmas 3, 4751 (1996).

[25] H. B. Valentini and D. Kaiser, Plasma Sources Sci. Technol. 23, 015004 (2014).

[26] H. M. Mott-Smith and I. Langmuir, Phys. Rev. 28, 727 (1926).

[27] M. A. Lieberman and A. J. Lichtenberg, Principles of Plasma Discharges and Materials Processing (John Wiley \& Sons, New York, 1994). 